\title{
SEIS PERSONAJES EN BUSCA DE "UN TERCER LUGAR". LA INSEGURIDAD Y AFÁN DE ENCONTRAR AL OTRO Y SÍ MISMO EN UN TERCER LUGAR DE DENISE DESPEYROUX
}

\author{
Natalia Szejko \\ 1. Instituto de Estudios Ibéricos e Iberoamericanos, \\ Universidad de Varsovia \\ 2. Departamento de Bioética, \\ Universidad de Medicina de Varsovia \\ https://doi.org/10.18778/8220-195-6.10
}

\section{Resumen}

Denise Despeyroux en su obra Un tercer lugar (2016) ofrece una propuesta irónica en torno a la vida humana y a las relaciones interpersonales. Los personajes de este drama están en un constante proceso de búsqueda de sí mismos, del cambio y la transformación. La inseguridad e inestabilidad de las relaciones interpersonales son los rasgos autistas que se enumeran en las teorías de la cognición emocional. El objetivo de mi ponencia es hacer un análisis del drama Un tercer lugar en el marco teórico de la teoría de la cognición emocional. Despeyroux presenta tres parejas neuróticas que se sienten incapaces de comprenderse. Los rasgos de la inestabilidad emocional y las diferencias de horizonte de expectativas son del máximo interés para la dramaturga.

Palabras clave: Denise Despeyroux, inseguridad, autismo, cognición emocional. 
El objetivo del presente trabajo es analizar la obra teatral Un tercer lugar de la dramaturga hispano-uruguaya Denise Despeyroux. Proponemos una lectura interdisciplinar que alude a las teorías de la cognición emocional y el autismo, ya que los personajes de esta obra demuestran un alto grado del neurotismo y, a pesar de buscar un vínculo emocional con otros seres humanos, se aíslan cada vez más debido a los fallos comunicativos.

Un tercer lugar fue estrenada el 16.11.2017 y nominada simultáneamente al Premio Max de las Artes Escénicas. La autora, Denise Despeyroux, nació en Montevideo, pero luego estudió Artes Escénicas y Filosofía en Buenos Aires y Barcelona. Fue finalista al Premio Max Revelación y candidata en la categoría de la mejor autoría y mejor actriz por la obra La realidad (2012). Despeyroux menciona que su formación internacional ha tenido mucha importancia en el desarrollo de su teatro:

Me licencié en Filosofía y me entregué apasionadamente al teatro desde los 12 años. Recibí mi formación principalmente en el Colegi del Teatre, el Estudio Nancy Tuñón y la sala Beckett. Pero fueron varios autores argentinos, especialmente Javier Daulte y Rafael Spregelburd, quienes me cautivaron como para seguirlos hasta Buenos Aires, donde pasé un par de temporadas de varios meses haciendo y viendo teatro. En el 2011 me instalé en Madrid y aquí continúo, escribiendo y dirigiendo. El teatro me sigue pareciendo una hermosa aventura colectiva y el mejor lugar donde conjurar todo lo que me inquieta (Despeyroux, 2019: 1).

De igual importancia fueron sus estudios en el campo de la filosofía ya que hace alusión a diferentes teorías filosóficas en sus obras de teatro.

En las acotaciones iniciales de Un tercer lugar se explica el título de la obra y, al mismo tiempo, el tema principal del drama. Se cita en este punto Ensayo sobre el cansancio de Peter Handke:

Parece ser una regla que hombre y mujer, antes de que por unas horas se conviertan en una pareja de ensueño, tienen que haber recorrido primero un camino largo y difícil y tienen que 
haberse encontrado en un tercer lugar, extraño a los dos, lo más lejano posible a cualquier tipo de patria o de confortabilidad doméstica. Y además, con anterioridad, tienen que haber superado un peligro o simplemente una larga confusión, en un país hostil, que también puede ser el propio (Handke, 2013: 14).

El "tercer lugar" es, entonces, un lugar utópico donde las dos personas llegan a un compromiso emocional. Es, al mismo tiempo, un sitio desconocido, hostil e inesperado, "un tercer lugar" ajeno al refugio seguro del individualismo. Para llegar a la compresión interpersonal tienen que sacrificar sus propias necesidades y someterlas al beneficio mutuo de la relación con el otro. Es, entonces, un lugar peligroso, en el que pueden aparecer conflictos e incomprensión y en el que se pone de relieve la debilidad de uno mismo. Por esa razón, una de las estrategias protectoras es escaparse al mundo propio y aislarse, demonstrando así los rasgos autistas.

Los personajes de Un tercer lugar se pueden acoplar en tres parejas de enamorados: Tristán y Matilde, Cordelia y Samuel, Carlota e Ismael. Todos ellos participan en diferentes acciones simultáneas y, a su vez, sus caminos se entrecruzan constantemente durante la obra. El drama se compone de quinze microescenas, cada una de ellas lleva un título que indica, de una manera humorística, cuál es el contenido y el sentido de la escena. Es menester mencionar en este punto que algunos títulos constituyen citas directas de obras filosóficas conocidas ("Que el sol haya salido hasta ahora todos los días no nos da derecho a suponer que el sol saldrá mañana", "Un perro lleno de dolor o de tristeza se vuelve pendenciero", "Existir es ser percibido"). Destacan aquí las alusiones filosóficas tan típicas de la dramaturgia de Despeyroux.

Ya en la escena primera, titulada "En mis diálogos llegamos los dos lejísimos", se demuestra la constante incomprensión interpersonal. Tristán habla con Cordelia, la mujer de la que está enamorado. Intenta conquistarla empleando un lenguaje poético y romántico. Tristán demuestra el amor caballeresco en que la persona querida es idealizada y convertida en un ser ideal, casi inexistente. 
TRISTÁN - Quiero enloquecerte de un vértigo repentino pero reversible. Quiero recorrer contigo todos los estadios del amor desordenados. Quiero que esparzamos juntos un rastro de sangre y esperma por el universo. Quiero mirarte la noche entera mientras finges que duermes y acariciarte como si no te quisiera despertar. Quiero que en todas nuestras riñas esté latente la reconciliación. Quiero que cada palabra que salga de mis labios te haga sentirte escogida. (Toca el acordeón)

TRISTÁN - Tú no te dejas seducir, Cordelia, ¿y sabes por qué? Porque no te dejas impresionar por las verdades ajenas. Aun así, sé que ya no te soy ajeno. Poco a poco, con mi obstinada manera de quererte, me he ido convirtiendo en alguien para ti... soy alguien para ti... me he vuelto imprescindible (Despeyroux, 2016: 4).

Desgraciadamente, todos los intentos de Tristán fracasan, Cordelia no responde a sus emociones, no le comprende y le rechaza constantemente:

CORDELIA - No tengo la cabeza para esto, Tristán. Ahora no, por favor. No puedo más. Yo ya no puedo más.

TRISTÁN - Entonces es el momento perfecto para que unamos nuestra impotencia.

CORDELIA - Deja de hablarme así. Deja de inventar escenas. Deja de disfrazarte. ¿Qué quieres de mí, Tristán? ¿Qué quieres de mí? (Despeyroux, 2016: 4).

Seguramente no son aquí casuales los nombres de los personajes. Tristán es uno de los caballeros más famosos de la literatura mundial, un prototipo casi mitológico del amor cortés, correspondido pero profundamente infeliz. Por otro lado, el nombre Cordelia puede referirse a una de las hijas de Rey Lear del drama de Shakespeare.

La escena segunda, "Puedo pedirte una pizca de sal", tiene lugar en un piso. Samuel va a la casa de su vecina, Cordelia, la mujer de la escena primera. Samuel aprovecha la excusa de pedir una pizca de sal para explicar a Cordelia su idea de la casa perfecta, la 
casa de sus sueños. Obviamente, no se trata de una casa real, sino imaginaria e inexistente, la casa metafórica que muestra todos los deseos imposibles de realizar:

SAMUEL - Sí, sí, será muy rápido. Mira, esta habitación de aquí, la primera, es el salón de mis sueños. Éstas son las puertas de mis sueños, y todas éstas las ventanas de mis sueños. Éste es el sillón de mis sueños, y ésta es la alfombra de mis sueños. Éstos son los cuadros de mis sueños y esto de aquí el espejo de mis sueños. Encima de esta repisa, que sería la repisa de mis sueños, estaría el adorno de mis sueños, y al lado esta puerta del color de mis sueños que se abriría al dormitorio de mis sueños. Y aquí estaría la cama de mis sueños con las sábanas de mis sueños y los cojines de mis sueños... Aquí las flores de mis sueños dentro del jarrón de mis sueños... (Despeyroux, 2016: 7)

Cordelia está cansada de los elogios continuos que recibe de su vecino, se siente espiada por él, pero Samuel explica que en su caso se trata de amor cortés en el que solamente uno tiene que participar activamente en la relación, mientras que el otro es una especie de objeto adorado:

SAMUEL - ¡Yo no la espío! ¡Yo solamente la contemplo! Con el corazón en vilo, con el respeto más sagrado que un ser humano puede guardar hacia otro ser humano, con estupor... ¿Cómo puede insinuar que la espío? Yo jamás haría una cosa así (Despeyroux, 2016: 9).

El carácter platónico de este sentimiento lo subraya el propio Samuel cuando explica en las escenas siguientes que basta solamente su amor para mantener la relación entre los dos. Está convencido de que al cabo de algún tiempo Cordelia también loamará:

SAMUEL - No tienes que hacer nada, Cordelia, de verdad que no tienes que hacer nada. He vivido quince años bajo el signo del miedo. El miedo a que se rompiera esta maqueta y el miedo a que mi amor se acabara un día. Porque en mi experiencia todo 
el que ama sin ser correspondido algún día acaba dejando de amar (Despeyroux, 2016: 37).

Sin embargo, a lo largo de la obra, Cordelia se resiste a amar y ser amada, su deprivación emocional la explica posteriormente otro personaje, Carlota, que describe la complejidad de la personalidad de Cordelia:

CARLOTA - Es usted la víctima ideal: dulce, ingenua, compasiva. Bella pero desolada por dentro aunque no se aprecie a simple vista. Un muro donde cualquiera puede escribir su deseo. Pero un muro al fin. Y un muro es un muro aunque le pongas flores. Sospecho que es usted en el fondo inaccesible, impenetrable como un bosque encantado. Porque hay bosques penetrables y bosques impenetrables... usted es un bosque impenetrable (Despeyroux, 2016: 35).

Estos deseos contradictorios pueden ser típicos del trastorno de la personalidad histriónica. Las inclinaciones histriónicas se pueden encontrar en todos los personajes de la obra de Despeyroux. El trastorno histriónico de personalidad se define como el desorden que se caracteriza por la inestabilidad emocional y la excesiva necesidad de aprobación. Para atraer la atención del otro, las personas se comportan de una manera infantil e inmadura. Por eso adoptan una manera dramática y exagerada de comportarse. Por otro lado, las personas afectadas por este trastorno buscan constantemente la atención del otro y pueden ser fácilmente influenciados por las opiniones de otros. Así es también Cordelia, frágil y sensible, pero vulgar al mismo tiempo. No obstante, es solamente una estrategia protectora que le permite esconderse ante un mundo hostil.

En la escena siguiente, titulada "Pájaros espías", conocemos a los personajes de Ismael y Carlota. Los dos representan dos mundos totalmente diferentes, él es un hombre simple e ingenuo, mientras que ella es una abogada y conocedora de filosofía. Los rasgos neuróticos de ambos y la incomprensión se presentan de una manera irónica a través de diferentes registros lingüísticos 
y alusiones a escuelas filosóficas. Esta técnica se pone de relieve en la escena siguiente que lleva el título: "Que el sol haya salido hasta ahora todos los días no nos da derecho a suponer que el sol saldrá mañana". Son las palabras del filósofo inglés David Hume que subrayan la inseguridad de la existencia. Esta inseguridad se canaliza en estos dos personajes opuestos, Ismael y Carlota. Mientras que Ismael representa lo sentimental, Carlota personifica lo racional. Al mismo tiempo, Ismael es muy simple y Carlota una persona muy compleja. Carlota intenta educar emocionalmente e intelectualmente a Ismael dando ejemplos del campo de la filosofía:

CARLOTA - Ismael, sí. Precioso nombre bíblico, significa Dios escucha. Entenderse se entiende, Ismael. El problema es que esto es un disparate.

ISMAEL - ¿Cómo que "y"? Pues que yo cada día venía a trabajar a la empresa y me encontraba la empresa abierta y entraba y es lógico que si no me dan ningún tipo de aviso de que la empresa va a cerrar y me van a despedir yo espere encontrar la empresa abierta.

CARLOTA - Claro, porque usted no ha leído a Hume. Ahí está el error.

ISMAEL - ¿Cómo?

CARLOTA - ¿Ha leído a Hume?

ISMAEL - No.

CARLOTA - ¿Ve? Por eso usted topa de lleno con el problema de la inducción. Que empíricamente una cosa haya demostrado ser siempre de la misma manera no nos da derecho a suponer que seguirá siendo siempre así (Despeyroux, 2016: 11).

A lo largo de la obra Carlota e Ismael leen juntos obras filosóficas e intentan entender mejor la realidad a través de ellas. Carlota recomienda lecturas a su acompañante y espera que así también mejore su vida: "CARLOTA - Anote el título del libro, le conviene leerlo: "Tratado sobre la naturaleza humana", de David Hume" (Despeyroux, 2016: 12). La relación entre los dos es cada vez más cercana, la filosofía les ayuda a entender las emociones propias 
y las del otro. En la escena sexta, titulada "Un perro lleno de dolor o de tristeza se vuelve pendenciero", Ismael y Carlota intentan encontrar juntos el equilibrio emocional. Los dos leen la obra de Hume, "Tratado sobre la naturaleza humana", y buscan en él el equilibrio emocional. Particularmente, les interesa la relación entre las emociones y experiencias del ser humano y cómo nuestras relaciones con los otros moldean nuestro comportamiento:

ISMAEL - Un perro, cuando se halla exaltado por la alegría es llevado naturalmente a sentir amor y ternura o por su dueño o por un individuo del otro sexo. Del mismo modo, cuando se halla lleno de dolor o tristeza se hace pendenciera, y esta pasión, que en un comienzo era tristeza, con la más mínima ocasión se convierte en cólera.

ISMAEL - Porque es verdad eso de que la tristeza se convierte en cólera. Yo eso lo veo por ejemplo en mi hermano (Despeyroux, 2016: 20).

El secreto de adaptarse a la realidad es la filosofía. Es interesante que Carlota e Ismael aluden a las obras de casi todas las épocas y pensamientos distintos: "CARLOTA. - Claro que sí. Usted y yo vamos a leer tanto... vamos a leer a Kierkegaard, a Benjamin, a María Zambrano... Descriteriadamente, sin ambición, con nostalgia y euforia" (Despeyroux, 2016: 20). Se nota que filosofía es para ellos un ejercicio intelectual, un juego que activa sus capacidades cognitivas y emocionales. Asimismo, en la escena séptima, "La margarita no es una flor", los mismos personajes discuten sobre Berkeley y Descartes e intentan llegar a la transformación a través de la filosofía:

CARLOTA - Ismael, has idealizado a Hume porque tienes idealizado el comienzo de nuestra relación. No es que Hume sea menos deprimente que Berkeley, lo que ocurre es que tienes un temperamento muy nostálgico y para ti cualquier tiempo pasado fue mejor.

ISMAEL - Siempre ha estado enamorado de una mujer, pero de pronto se enamoró de otra y no sé... no sé muy bien qué le 
pasa exactamente. Yo tengo la sensación de que la quiere pero no quiere quererla... algo así. Crees que leer a Berkeley... bueno, leer filosofía en general... ¿ puede ayudarme a comprender mejor todo este tipo de cosas? (Despeyroux, 2016: 43).

Poco a poco los dos se enamoran, Carlota se rinde ante el cariño de Ismael, mientras que Ismael se siente fascinado por la inteligencia de su amada. Carlota impulsa a Ismael a cambiar constantemente, a superar sus propios complejos e inseguridades. Su mutua existencia es necesaria para sobrevivir, el amor y aceptación les dan fuerzas para avanzar hacia delante, porque "existir es ser percibido" (Despeyroux, 2016: 43).

La tercera pareja de sujetos neuróticos es Tristán y Matilde. Los conocemos en la escena quinta, “¿Por qué iba a financiar la embajada de Noruega a un dramaturgo danés?". Los dos se conocen durante una obra del teatro y se enamoran casi a primera vista:

TRISTÁN - Lo siento... ¿quieres salir? ¿Quieres que te acompañe?

MATILDE - No, no, si me encanta la obra. Tranquilo, estoy bien, es sólo una ligera sensación de ahogo, y también de vértigo, como si fuera a caerme del mundo. Entendiendo por mundo esa delgada red llena de agujeros que nos sostiene a veces, ya sabes... Pero creo que resistiré hasta el final de la obra. Si veo que me pongo realmente muy mal, te lo digo (Despeyroux, 2016: 15).

En las escenas siguientes, somos testigos de sus posteriores encuentros y aunque su relación cambia y empiezan a ser pareja, al mismo tiempo demuestran rasgos profundamente neuróticos. Buscan el encuentro con otro ser humano, pero tampoco se fían de él. Sus reacciones sociales se reducen cada vez más y no saben reaccionar a las emociones y necesidades del otro. Este tipo de comportamiento también se puede interpretar en el marco del trastorno de apego que se manifiesta en la forma de una persistente incapacidad para iniciar o responder a la mayoría de las interacciones sociales. Por otro lado, el comportamiento de Matilde 
y Tristán puede también ser la repercusión de la ansiedad ante una nueva relación o el trastorno de personalidad ansiosa. Poco a poco empiezan a enterderse cada vez menos, se sienten cada vez más aislados:

TRISTÁN - No, no veo que esto nos acerque, veo que nos separa. Veo que los dos tenemos demasiados problemas como para estar juntos. ¿No entiendes que yo me he leído casi todos los libros de esa colección y resulta que los autores no existen? Resulta que no los ha escrito gente iluminada, gente que ha cambiado su ser y su vida entera por una revelación sino gente desgraciada y corriente como tú.

MATILDE - ¿Tú a mí me ves desgraciada y corriente? (Despeyroux, 2016: 28).

Matilde clasifica su estado de tristeza redirigida que se caracteriza por la necesidad de apego y que deriva de su depravación, pero causada por el sujeto mismo, o sea, que constituye la demonstración de inclinaciones autodestructivas. Finalmente, la tristeza acumulada se canaliza en emociones negativas presentadas ante los otros y reacciones irracionales:

\begin{abstract}
MATILDE - Lo que te estoy intentando explicar es que eso sucede también entre las personas y sucede además de con la ira con la tristeza. Digamos que yo tengo por dentro una gran cantidad de tristeza acumulada, ¿sí? Tristeza que no tiene nada que ver contigo. Y de repente tú dices algo que activa todo ese sentimiento que está ahí de antes y de otras cosas y parece que yo me haya puesto triste por algo que tú has hecho o dicho, pero en realidad no es así, ¿entiendes? (Despeyroux, 2016: 28).
\end{abstract}

Es curioso que todos los personajes compartan esta inclinación por las reacciones irracionales y exageradas, la relación entre estas tres parejas se subraya también a través de la organización del espacio escénico que está dividido en tres microespacios presentados simultáneamente en la escena décima: 
Tres imágenes conviven en el escenario, en diferentes espacios, cada una con su particular iluminación. Al fondo, Ismael y Carlota comparten la lectura del Tratado sobre la naturaleza humana, de David Hume. Toman notas, discuten, parecen muy enfrascados en el asunto; no existe nada más. En el centro Tristán y Matilde se abrazan, se besan, se miran a los ojos y se vuelven a besar; no existe nada más. En proscenio Samuel contempla mudo y estupefacto la maqueta de la casa de sus sueños, que está en el suelo hecha pedazos, mientras Cordelia contempla a Samuel, impotente y conmovida; no existe nada más (Despeyroux, 2016: 36).

Se puede interpretar también el comportamiento de los personajes como la manifestación del temor ante la soledad, pero también ante las relaciones interpersonales. Cuando Matilde y Tristán se separan, Matilde no puede superarlo y decide suicidarse, algo que puede parecer una reacción exagerada en este caso. Es un síntoma de la inmadurez emocional típica de todos los trastornos mencionados anteriormente:

Deseo de vivir. Dos puntos y tres alternativas: de moderado a fuerte/ débil /o ninguno. ¿Tú habrías sabido qué responder? Yo habría dicho intenso, mi deseo de vivir es intenso. Por eso mismo pienso tanto en morirme. Razones para vivir, barra, morir. Yo pensé que habría un abanico, y pensé que tal vez encontraría allí las mías... mis razones para vivir o para morir. Pero no, solo se trataba de cuantificar razones, no de examinarlas (Despeyroux, 2016: 47).

La obra concluye con reflexiones generales en torno a las relaciones interpersonales. Casi todos, a parte de Ismael y Carlota, fracasan en su intento de construir una relación satisfactoria. Permanecen en el nivel de la imaginación, en búsqueda de un tercer lugar:

Lo sé, y lo siento. Siento nostalgia de lo que no ha llegado a ser, echo de menos lo que no llegamos a vivir juntos, sufro la traición de promesas que no llegamos nunca a pronunciar. Como 
si lo más importante entre nosotros hubiera sido siempre tácito, silencioso, pero a la vez verdadero e imposible de disimular. Cada vez que recuerdo mi mano entre las tuyas tiemblo de tristeza como si hubiera perdido mi único hogar (Despeyroux, 2016: 49).

Se puede concluir entonces que Un tercer lugar es un ejemplo de obra que se puede interpretar desde diferentes puntos de vista. Desde la perspectiva psicológica, los personajes neuróticos creados por Despeyroux manifiestan un trastorno reactivo del apego, de ansiedad o un trastorno histriónico de la personalidad, mientras que desde el punto de vista filosófico y estético-formal se trata de una obra que explora los temas de la incomprensión interpersonal utilizando los medios adaptados de textos filosóficos.

\section{Bibliografía}

Ballester, G., Molero Mañes, C., Rosa, J., Gil Llario, Ma D. (2014). "Desorganización del apego y el trastorno traumático del desarrollo", International Journal of Developmental and Educational Psychology: INFAD. Revista de Psicología, N. ${ }^{\circ}$, Vol. 3, 375-380.

Despeyroux, D. (2016). Un tercer lugar. Bilbao: Artezblai.

Despeyroux, D. "Contexto teatral”, [en línea], <http://www.contextoteatral.es/denisedespeyroux.html $>$ [30.01.2019].

Handke, P. (2013). Ensayo sobre el cansancio. Barcelona: Alianza. López-Ibor A., Juan J., Valdés Miyar, M. (2002). DSM-IV-TR. Manual diagnóstico y estadístico de los trastornos mentales. Texto revisado. Barcelona: Editorial Masson.

Pérez, E., González, A., Moreno, A., Ponte, N., Delgado M. (1997). "Personalidad histérica o trastorno de personalidad histriónico: una revisión”. Revista de Asociación Española de Neuropsiquiatría, Vol. XVII, 62, 223-236.

Tortella-Feliu, M. (2014). "Los trastornos de ansiedad en el DSM-5". Cuaderno de Medicina Psicosomática y Psiquiatría de enlace. Revista Iberoamericana de Psicosomática, N. ${ }^{\circ} 110$, 62-69. 